\title{
Energy Efficient Buildings as a Tool for Ensuring Sustainability in the Building Industry
}

\author{
A. Mohammed ${ }^{1}$, A. Mustapha ${ }^{2}$, N. Mu'azu ${ }^{3}$ \\ Civil Engineering Programme, Abubakar Tafawa Balewa University, PMB 0248 Bauchi, Bauchi State, Nigeria \\ Civil Engineering \& Water Resources Engineering Department, University of Maiduguri, PMB 1069 Borno State, Nigeria \\ 1abbaganam@gmail.com \\ 2almus_2@yahoo.com \\ ${ }^{3}$ muaazu@yahoo.com
}

\begin{abstract}
The building industry is the greatest consumer of energy worldwide, as such any measures taken by the industry to improve energy efficiency in our buildings will have a desirable effect in the reduction of carbon emissions into air. The paper discusses the concept of embodied energy or carbon of building materials as well as the concept of running or operational carbon. It further highlights strategies that could be used by the various stakeholders in the building industry; namely the building materials producers, builders, designers and governments to improve energy efficiency in buildings. It also shows that for the strategies to work, they must be part of a building industry policy in order to achieve an industry wide implementation of the measures.
\end{abstract}

Keywords-buildings, energy efficiency, embodied energy, embodied carbon, sustainability)

\section{INTRODUCTION}

The drive towards more energy efficient and sustainable resources, materials and processes is increasingly gaining momentum because of the need to preserve our fragile ecosystem in light of the climate change question. Emissions from fossil fuel based industries have been blamed for the greenhouse effect that has resulted in a warming of global temperatures and altering the weather pattern all over the world. The shift from fossil fuel to renewable sources is slowly gathering pace as a way to limit the detrimental effects of these emissions. However, there have been challenges in harnessing renewable energy because of the high capital costs and Nuclear power is thought to be too risky. Accordingly, the need for energy efficiency in all industries is seen as one way of checking the harmful effects of the emissions. The building industry is the greatest consumer of energy in the world responsible for $40 \%$ of all energy used in society [1]. For example in the UK, buildings consume approximately about 50\% of all energy use, transport accounts for $25 \%$ while the balance is taken up by industry [2]. In the developing countries buildings consume about a third of all energy use [3]. This underlines the need for professionals in the built environment to come together and look at ways of addressing the unsustainable use of energy in buildings, with a view to charting a road map towards more sustainable building materials, technologies and use.

To this end, professionals in the industry will need to know how the choice of building materials affect the total embodied energy content of a building; how much energy is used in construction and how this can be minimized; how substitutions between materials might be made to save energy without sacrificing performance in other respects; and how building materials selection affects the lifetime energy consumption of a building, including manufacture, construction, use and maintenance, and demolition.

What is even more challenging is the fact that the rate of growth in energy consumption in the world is more than the rate of population growth and as more buildings are being built to bridge the housing deficit in the country, there are opportunities for huge energy savings through proper design, construction and materials selection by professionals in the building industry.

\section{EMBODIED ENERGY, EMBODIED CARBON AND BUILDINGS}

Carbon emissions can arise from building through five ways as enumerated below using the Life Cycle Analysis (LCA) which is defined as the investigation and evaluation of the impact of a given product or service. A full LCA should consider all stages of the product (building) life: 'production' (of the raw materials), 'manufacture' (construction), and 'use' (operational energy) and 'disposal' (demolition). [4]

- Management Carbon (Mc) - the off-site cost of managing the delivery of a project - customer, consultants, contractor, etc

- Embodied Carbon in materials (Ec) - the carbon impact of the extraction, production and assembly of the raw materials and components of a project.

- $\quad$ Construction Carbon (Cc) - the carbon input required assembling the building on site

- Operating (running) Carbon (Oc) - the cost of operating and maintaining the building through its working life

- Deconstruction Carbon (Dc) - the impact of taking apart the building at the end of its life, and recovering materials for reuse or recycling, landfilling or other disposal [5].

Embodied energy is defined here as the energy required in manufacturing and supplying to the point of use, a building material. 
Fig. 1 shows typical whole life carbon emissions for new buildings in the UK. Of the total (the Whole Life Carbon, WLc), embodied carbon (Ec), and operating carbon (Oc) from the use of the building ( mainly to heat the building in the temperate zone and cool/heat in the tropics) are the two major contributors. At present, the focus is on reducing operating emissions ('zero-carbon buildings'), an area in which the structural engineer can make some contribution, but which is primarily driven by the architects. However, the frame and envelope of the building contain a relatively large proportion of the project's embodied carbon, and it is in this area that Architects and Structural Engineers can make a significant impact by specification of low carbon materials and structural details.

\section{EMBODIED ENERGY CONTENT OF BUILDING MATERIALS}

Because of the need to reduce the embodied energy component in Fig. 1 (which is the second highest component), designers need to know how energy can be saved by the selection of one building assembly, building component or complete building system rather than another, when both alternative systems have comparable capital costs and can satisfy all the structural and functional requirements - in terms of strength, stiffness, thermal performance etc.

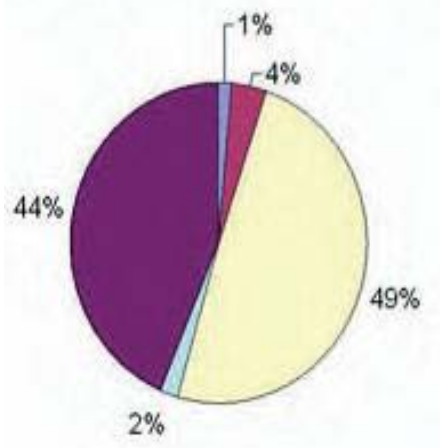

\begin{tabular}{|l|}
\hline Project Management \\
$\square$ Construction process \\
$\square$ Operation \\
$\square$ Demolitions \\
$\square$ Materials
\end{tabular}

Figure 1. Whole life carbon emissions of new buildings in 2007 [6].

An interesting simplified perspective on the energy efficiency of different materials in relation to performance is given by comparing the energy costs of obtaining one unit of some property the building designer is interested in using a range of materials. For use as structural materials, it is the stiffness of the material which is of greatest importance, since this governs both the deflection of beams and slabs and the buckling of columns. Knowing the energy cost per unit volume and the stiffness coefficient (elastic modulus) of the material a comparison can be made of the energy cost of different materials per unit of stiffness. Table 1 shows some typical figures for a range of commonly used materials. They show that, in these terms, timber is the most energy efficient commonly used material for use in structures, being several times more efficient than steel or reinforced concrete. They also show that the use of aluminum for structural purposes is extremely expensive in terms of energy utilization; thus where aluminum is preferred to other materials for some reason (such as for instance, its resistance to corrosion) there is a heavy energy cost penalty to be paid [7].

\section{ENERGY CONSUMPTION/USE IN BUILDINGS}

Energy use in buildings as seen in Fig. 1 constitutes the greatest source of emissions from buildings. Fig. 2 shows how energy use in buildings is constituted. Air conditioning by far is the greatest source of energy consumption followed by lighting This is to be expected, since most of our buildings are deficient in thermal comfort design, therefore some other means of bringing about the indoor temperature to comfortable limits must be resorted to (and of course nothing can beat air conditioning in this regard). Hence, if the initial design considers energy efficiency measures in these areas, substantial energy savings can be realised.

TABLE I. ENERGY REQUIREMENT FOR ONE UNIT OF STIFFNESS OF DIFFERENT MATERIALS [6]

\begin{tabular}{|l|l|l|l|l|}
\hline \multicolumn{1}{|c|}{ Material } & \multicolumn{1}{|c|}{$\begin{array}{c}\text { Elastic } \\
\text { modulus, } \\
\mathbf{E} \\
\left(\mathbf{M N} / \mathbf{m m}^{\mathbf{2}}\right)\end{array}$} & $\begin{array}{c}\text { Density } \\
\mathbf{( k g / \mathbf { m } ^ { 3 } )}\end{array}$ & $\begin{array}{c}\text { Energy } \\
\mathbf{( k J / k g}\end{array}$ & $\begin{array}{c}\text { Energy cost of } \\
\mathbf{u n i t} \text { of } \mathbf{E}\end{array}$ \\
\hline Timber (sawn) & 110000 & 500 & 1170 & 53 \\
\hline Mass concrete & 14000 & 2400 & 720 & 124 \\
\hline Brick & 30000 & 1800 & 2800 & 167 \\
\hline $\begin{array}{l}\text { Reinforced } \\
\text { concrete }\end{array}$ & 2700 & 24000 & 8300 & 738 \\
\hline Steel & 210000 & 7800 & 43000 & 1598 \\
\hline Aluminium & 70000 & 2700 & 238000 & 9180 \\
\hline
\end{tabular}
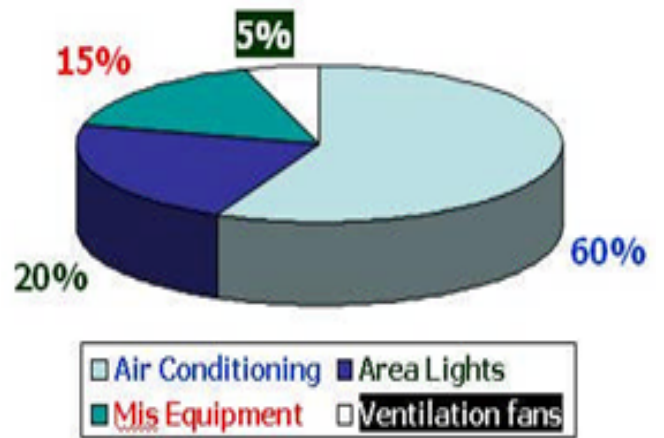

Figure 2. Break up of Energy Consumption in a Building [7]

\section{STRATEGIES FOR OPTIMIZING ENERGY USE IN THE BUILDING INDUSTRY}

\section{A. Role of Producers of Building Materials}

The energy consumption in the production of building materials accounts for a high proportion of the total embodied energy in buildings, and thus improvement of energy use in production processes is a crucial part of any overall strategy for energy conservation in the built environment. Much of the energy use in building materials takes place in the manufacture of a few extensively used materials which involve high temperature kiln processes, notably iron and steel, cement, clay bricks and tiles and glass, and energy saving strategies should concentrate on these processes. A second area of significant energy use is for mechanical plant used for quarrying, conveying, crushing and grinding materials in manufacturing processes. A third is low temperature processes such as drying 
and autoclaving. A fourth is in the transport of materials both from quarries to the production plant, and from the factory to the site or the local distributors.

Because of the high energy intensities of many production processes, larger producers using modern technologies (for example, cement producers) are generally mindful of the need for energy efficiency, and can be expected to undertake many of these measures without additional incentives, in order to reduce production costs. However, many of the small scale producers of building materials using traditional processes are usually slow to respond to changing pressures or alter established practices. Thus policy makers and government departments have a role to assist building materials producers improve their energy efficiency in the ways enumerated under strategies for governments.

\section{B. Role of Builders}

Construction activity accounts for a small but important proportion of the embodied energy in buildings, ranging from about 15 to 35 per cent of the embodied energy. A large part of the energy use in construction is related to the use of mechanical plant for transporting, levelling, digging, lifting, compacting and mixing, while a second significant component relates to the energy use in the buildings both temporary and permanent used by the builder for the construction activity. Energy embodied in materials used for temporary works scaffolding and formwork for concrete, for example forms a third component [8].

Construction efficiency also, to some extent, affects the total amount of embodied energy in the building, since inefficient site management can result in considerable materials wastage. For example, it has been estimated that on typical urban construction sites in developing countries more than 25 per cent more cement is used than would be needed if quality control was improved. In other cases, excess material is used over the amount specified in the design (for example, in trench foundations) to reduce time and labour cost.

The decisions of the builder may also dictate the sources of supply of the materials used in a building, and hence determine the transport energy component of the embodied energy, which is often significant. Conducting energy audits on typical construction sites to identify energy use and energy saving opportunities also goes a long way in making site staff aware of the energy implications of all site activities, and introducing incentives for energy saving. The contractor could also examine the energy efficiency of all mechanical plant used; replacing inefficient plant with more efficient plant; reducing the unnecessary use of plant; ensuring that all plant is properly serviced and maintained (poor maintenance can increase energy use by 180 per cent); considering the selective replacement of mechanical plant with the use of manual labour. most of these strategies will prove cost effective to implement, so it should be possible to persuade builders to implement them without additional financial incentives, once they have been identified.

\section{Role of Designers}

Over 80 per cent of the embodied energy in a building is the energy required to manufacture the materials. It has also been shown that most of this energy is used in only a small number of the materials used in building, principally iron and steel products, cement and concrete products, bricks and ceramic materials. Moreover, the embodied energy in a building amounts to several times the annual energy consumption of that same building in use.

Thus designers have the opportunity to make a major contribution to the reduction of the total energy use in the built environment through strategies such as the use of less high energy materials, in building design; looking for ways to reduce the thickness of walls, finishes, storey heights etc., where this can be done without compromising other aspects of performance.

Selection of low energy materials rather than higher energy alternatives when these are available is also one way through which designers can contribute to sustainability. Some examples are; use of timber in place of steel or concrete for beams and trusses, use of lime pozzolana mortars in place of cement mortars, use of soil and stabilized soil blocks, rammed earth or sand lime bricks rather than clay bricks, use of masonry domes and vaults in place of roof trusses.

Energy efficiency can also be ensured by use of lower energy structural systems, such as use of load bearing masonry in place of reinforced concrete or steel frames. And selection, where possible, of waste or recycled materials, or manufactured materials which incorporate for example, Portland pozzolana cements using Rice Husk Ash or Saw dust ash; asphaltic roof sheets incorporating recycled paper, building boards from agricultural waste, use of second hand or reclaimed building materials. Another way designers can contribute to energy efficiency is by designing for the use of materials which are found near to the site and have low transport costs.

These strategies will not always be consistent with strategies for saving energy consumption in the use of a building, and in such cases it is necessary to examine the total energy consumption over a building's lifetime to determine which is the optimum energy saving strategy. On the whole it is necessary to refocus design considerations from the traditional value for money approach into a strategy that also considers resource efficiency issues for structural engineers to make any appreciable impact in achieving energy efficient building design. [9]

\section{Role of Professional Institutions}

Professional institutions that contribute manpower to the building industry have a key duty to play in ensuring that their members are sensitized on the importance of energy efficiency in buildings. Various professional institutions like Institution of Structural Engineers UK and Institution of Civil Engineers UK have published various guides and established committees to provide essential technical guidance on the general importance of sustainable construction and design. Such efforts go a long way in providing useful information to building professionals through the Continuing Professional Development mechanism of such institutions. Some of the measures taken by such institutions include publishing of guidance on sustainability, holding evening lectures and conferences/workshops etc. 


\section{E. Role of Governments}

Federal State and Local governments being the main policy initiators, and implementers have a crucial role in promoting energy efficiency in the built environment by Supporting research into methods of improving energy efficiency of traditional energy intensive building materials production technologies, such as brick and tile manufacture, lime manufacture; helping to promote the transfer of improved technologies in the industry through meetings and demonstration projects. For Example, the federal government could easily mandate its agencies like the Energy Commission of Nigeria and the Nigerian Building and Road Research Institute to carry out such research on behalf of the government

Governments could also offer incentives to producers to undertake energy audits. They could also support studies to examine the effects on materials properties of altering raw materials to reduce energy, for example the replacement of Portland cement with a Portland pozzolana cement; helping to promote the application of low energy materials by designers and in the construction industry. Also formulating a building materials policy that permits the use of low energy materials, particularly new or unfamiliar ones; utilizing them in building projects using public funds.

Another key strategy for governments is the provision of incentives, where national economic considerations conflict with the financial interests of builders, to invest in energy saving through for instance replacing or upgrading inefficient plant, or through the use of manual labour in place of mechanical plant. And also by mandating the various Institutions where civil engineering, building engineering/technology and architecture are taught, to introduce course content that teach the fundamentals of Energy and Buildings in line with global best practices in the area of energy efficiency/conversation.

It is also important for the main central governments to formulate a green building design and assessment system and process in the mould of the US's green building council's Leadership in Energy and Environmental Design (LEED) or UK's Building Research Establishment Environmental Assessment Method for Buildings (BREEAM). These design and assessment methods are already used in many countries globally albeit with local variations to account for country specific peculiarities. Adoption of these assessment methods can thus be undertaken by governments at minimal cost.

\section{NEED FOR A BUILDING MATERIALS POLICY FOR NIGERIA}

The foregoing has shown the strategies required by the various stakeholders in the building industry for the attainment of energy efficiency in the industry. However, for such measures to work there must be a framework that sets out specific targets, requirements, procedures etc, for implementation. This underlines the need for a building materials policy that will be the blue print for espousing how Nigeria can achieve her goals for addressing the housing deficit in the country through sustainable construction by the utilization of energy efficient building materials. The urgent need for such a policy is necessary in order to reduce the Carbon emissions into the atmosphere for which the industry is the greatest culprit. Such a policy as part of the vision 2020 document will put the country on the right track to develop and grow the industry sustainably as the nation moves towards addressing her numerous developmental challenges.

\section{CONCLUSIONS}

The building industry is the highest energy consumer among all other industries, consequently opportunities abound for proactive measures aimed at implementing energy efficient strategies that will conserve energy and limit the harmful effects of the greenhouse gases on the environment. All players in the industry; producers of building materials, builders and designers have important roles to play in this regard, and more importantly is the role of government in supporting the industry through incentives as well as establishing the necessary framework for the formulation of a well thought out building materials policy that aims at implementing energy efficient measures in building construction.

\section{REFERENCES}

[1] Berge, B. (2009). Ecology of building materials, $2^{\text {nd }}$ Edn Elsevier, Oxford.

[2] Marsh, R. (1991). Discussion on: The energy of a building, The Structural Engineer, 69 (20), 296-299.

[3] US Congress; Office of Technology Assessment, (1991) Energy in developing countries- OTA-E-486, U.S. Government Printing Office, Washington, DC.

[4] Symons, K and Symons, D, (2009) . Embodied energy and carbon what engineers need to know, The Structural Engineer, 87(9), 19-23.

[5] IStructE Sustainable Construction Panel. (2008). What is embodied carbon?, The Structural Engineer, 86 (16), 13.

[6] Smith, B.P. (2008), Whole -life carbon footprinting, The Structural Engineer, 86(6), 15-16.

[7] Confederation of Indian Industry (2005), Energy Efficiency in Building Design and Construction (online) http://www.climatechallengeindia.org/Download-document/113-Energyefficiency-in-building-design-and-construction.

[8] UN Habitat. (1991). Energy for Building- Improving Energy Efficiency in Construction and in the Production of Building Materials in Developing Countries, Nairobi

[9] Borchers, M, (2010). Impotance of structural engineering in sustainable and low carbon design, The Structural Engineer, 88 (9) 14-16. 